\title{
Table of Contents
}

\section{Journal of Global Information Management}

Volume 25 • Issue 1 • January-March-2017 • ISSN: 1062-7375 • eISSN: 1533-7995

An official publication of the Information Resources Management Association

\section{Research Articles}

The Impact of Salient Cultural Practices on the Outcome of IS Implementation

Mumin Abubakre, Management Department, Nottingham Trent University, Nottingham, UK

Crispin R. Coombs, Loughborough University, Loughborough, UK

M. N. Ravishankar, School of Business and Economics, Loughborough University, Loughborough, UK

Consumers' Perceptions of Item-Level RFID Use in FMCG: A Balanced Perspective of Benefits and Risks

Wesley Kukard, Department of Business Information Systems, Auckland University of Technology, Auckland, New Zealand

Lincoln Wood, Graduate School of Management, The University of Auckland, Auckland, New Zealand and School of Information Systems, Curtin University, Bentley, Western Australia, Australia

Ikram Ullah Khan, School of Management, University of Science and Technology of China, Hefei, China Zahid Hameed, School of Management, University of Science and Technology of China, Hefei, China Safeer Ullah Khan, Donlinks School of Economics and Management, University of Science and Technology Beijing, Beijing, China

\begin{abstract}
Enhancing the Decision Quality through Learning from the Social Commerce Components
Aihui Chen, College of Management and Economics, Tianjin University, Tianjin, China

Yaobin Lu, School of Management, Huazhong University of Science and Technology, Wuhan, China

Sumeet Gupta, Indian Institute of Management Raipur, India
\end{abstract}

\section{COPYRIGHT}

The Journal of Global Information Management (JGIM) (ISSN 1062-7375; eISSN 1533-7995), Copyright (C) 2017 IGI Global. All rights, including translation into other languages reserved by the publisher. No part of this journal may be reproduced or used in any form or by any means without written permission from the publisher, except for noncommercial, educational use including classroom teaching purposes. Product or company names used in this journal are for identification purposes only. Inclusion of the names of the products or companies does not indicate a claim of ownership by IGI Global of the trademark or registered trademark. The views expressed in this journal are those of the authors but not necessarily of IGI Global.

The Journal of Global Information Management is indexed or listed in the following: ABI/Inform; ACM Digital Library; Aluminium Industry Abstracts; Australian Business Deans Council (ABDC); Bacon's Media Directory; Burrelle's Media Directory; Cabell's Directories; Ceramic Abstracts; Compendex (Elsevier Engineering Index); Computer \& Information Systems Abstracts; Corrosion Abstracts; CSA Civil Engineering Abstracts; CSA Illumina; CSA Mechanical \& Transportation Engineering Abstracts; Current Contents ${ }^{\circledR} /$ Social \& Behavioral Sciences; DBLP; DEST Register of Refereed Journals; EBSCOhost's Business Source; EBSCOhost's Computer \& Applied Sciences Complete; EBSCOhost's Computer Science Index; EBSCOhost's Current Abstracts; EBSCOhost's Library/Information Science \& Technology Abstracts with FullTEXT; Electronics \& Communications Abstracts; Emerald Abstracts; Engineered Materials Abstracts; Gale Directory of Publications \& Broadcast Media; Google Scholar; INSPEC; Internet \& Personal Computing Abstracts; ISBIB; Journal Citation Reports/Social Sciences Edition; JournalTOCs; KnowledgeBoard; Library \& Information Science Abstracts (LISA); Library Literature \& Information Sciences; Materials Business File - Steels Alerts; MediaFinder; Norwegian Social Science Data Services (NSD); PubList.com; SCOPUS; Social Sciences Citation Index ${ }^{\circ}$; Social Scisearch $\AA$; Solid State \& Superconductivity Abstracts; The Index of Information Systems Journals; The Standard Periodical Directory; Thomson Reuters; Ulrich's Periodicals Directory 


\title{
The Impact of Salient Cultural Practices on the Outcome of IS Implementation
}

\author{
Mumin Abubakre, Management Department, Nottingham Trent University, Nottingham, UK \\ Crispin R. Coombs, Loughborough University, Loughborough, UK \\ M. N. Ravishankar, School of Business and Economics, Loughborough University, Loughborough, UK
}

\begin{abstract}
Some information system (IS) studies have adopted organisational culture (OC) theory to investigate IS implementations. The studies highlight that members will reach consensus or agreement in the use of an IS but also experience inevitable tensions and ambiguities in the utilization of the IS. However, literature related to IS implementation/OC has rarely examined the influence that the saliency of specific cultural practices may have on the success or failure of IS implementations. Using a case study approach, we adopted the "soft positivism" research philosophy to collect data, underpinned by Martin's (1992) integration and differentiation perspectives of OC to study the organisational implementation of an IS. These perspectives served as interpretive lenses through which to explain how members' salient behaviours towards an IS evolved during the implementation process. Our study augments the IS implementation/OC literature by demonstrating how salient cultural practices influence the outcome of IS implementation.
\end{abstract}

\section{KEYWORDS}

IS implementation outcome, IS success/failure, organisational culture

\section{INTRODUCTION}

In many cases, the failure of an information system (IS) is due not to technical deficiencies, but to organisational issues such as user resistance or resistance to new working practices engineered by the introduction of the system (Rivard, Lapointe, \& Kappos, 2011; Wagner \& Newell, 2011). Thus IS failure may be due to a gap between members working values/practices and the implemented IS, or an organisation's inability to clearly recognise how its members different operating values/practices impact IS implementation processes/activities or vice-versa. Thus, many IS implementation studies have adopted organisational culture (OC) theory (e.g. Alavi, Kayworth, \& Leidner, 2006; Iivari \& Huisman, 2007) to explain how members respond to ISs in their everyday work, and how these responses influence the implementation process.

The aforementioned examples of IS-culture studies suggest that culture at the organisational level is delicate and has a strong influence on how organisations may cope with, and adapt to, organisational issues that emerge during the implementation of an IS. These studies have assumed that organisational groups/members will always have the same perceptions of, and behaviours toward, an implemented IS. However, Reinecke \& Bernstein (2013 p. 429) argue, "culture does not produce groups of people with uniform codes of behaviour, but creates groups that share similar thinking to some extent," suggesting that culture is not always homogenous. Therefore, there is a need to address the likelihood 
of competing cultures, conflicts and opposing IS outcomes arising among organisational subgroups when an IS is implemented (Ravishankar, Pan, \& Leidner, 2011). Organisational subgroup members who have different job functions are likely to have different interpretations and attitudes towards an IS in their attempts to develop and use the system (Koch, Leidner, \& Gonzalez, 2013; Wagner \& Newell, 2011). Thus, a consideration of culture that is limited to the organisational level may be insufficient to understand the outcome of IS implementation (Rivard et al., 2011).

To facilitate richer interpretations of organisational implementations of IS, studies have investigated culture at the subgroup level to explain how IS development and IS use can be impacted by subgroups that are in conflicting relationships with one another (e.g. Ravishankar et al., 2011; Rivard et al., 2011). We argue that considering OC and organisational subcultures as firmly grounded concepts provide nuanced explanations of how members' values, beliefs and practices at the organisational and subgroup levels influence the development and usage of IS. Despite the extant literature, indicating the apparent strengths of adopting the organisational and subgroup perspectives of culture to investigate IS implementations, it remains to be seen, the influence the saliency of specific cultural practices may have on an IS implementation outcome - that is, IS failure or IS success (Rivard et al., 2011). Exploring this would facilitate explanations of how and why members' interpretations and behaviours towards an IS are shaped and may change during implementation processes, and how OC influences implementation outcomes. This view contributes to the emergent view identified by some IS-culture studies that the relationship between culture and IS efforts are continuously evolving and dynamic (e.g. Gallivan \& Srite, 2005; Iivari \& Iivari, 2011; Leidner, 2010).

We predict that taking the evolving and dynamic view of culture will help advance our understanding of IS implementation, and explain how and why ISs fail or succeed. This will help organisations draw attention not only to organisation-wide practices but also to deviances among subgroups. In turn, organisations implementing IS cannot only take a 'top-down' organisational-level approach but also understand 'bottom-up' responses to the implementation process, consequently providing a better chance for IS success. We take organisational values to be appropriate to understand OC because the interpretations of values reflect deep assumptions (Martin, 2002). Therefore, our primary research question is: How do salient organisation-wide and subgroup values influence the outcome of IS implementation? To answer this question, we draw on Martin's (1992) perspectives of OC to examine the impact that integrated and differentiated values may have on the outcome of an IS implementation.

The next sections provide an overview of the extant research on organisational implementations of IS, before briefly reviewing the OC literature with particular reference to the impact on IS implementations. Subsequently, we outline our methodology, followed by our results, discussion, and conclusion.

\section{ORGANISATIONAL IMPLEMENTATIONS OF IS}

IS implementation studies focus on adoption decisions and post-adoption activities, to explain the challenges organisations face during attempts to achieve a successful implementation outcome (see Cooper \& Zmud, 1990; Zhu, Kraemer, \& Xu, 2006). These said studies suggest that to make successful IS implementation, majority of organisational members must use the implemented IS in an effective and efficient manner to facilitate full implementation of the system into the organisational settings. More recently, Burton-Jones \& Grange (2012) also highlight the importance of the "effective use", a concept to helping organisations achieving their goals for implementing and IS. Work of Bagayogo, Lapointe \& Bassellier (2014) complements Burton-Jones \& Grange's (2012) view of effective IT use. Bagayogo et al. (2014) provide insights into the dynamics involved in user interactions with IS by offering a slightly different conceptualisation to effective use. They introduced the concept of enhanced IS use to explain patterns of feature use that could affect effective use, vital for achieving organisational goals and organisational performance during IS implementation. Nonetheless, Burton- 
Jones \& Grange (2012) draw attention to the fact that an IS implementation outcome is dependent not only on the system but also included the organisational members and their context of use of the system i.e. organisational factors. Mishra \& Agarwal (2010) offer more elaborate explanations on how organisational factors influence IS implementation. They draw on managerial and organisational sensemaking and the organisational capabilities literature to develop and propose a model to understand the continued use of IS. The results from their model testing suggest that organisations' sense and response capabilities significantly influence organisational decision-making about IS use. In a different study, McMaster \& Wastell (2005) investigated how IS members of a local government agency developed and deployed a Business Process Re-engineering (BPR) system. McMaster \& Wastell (2005) point out, factors such as strong leadership, engagement of organisational members and the fortuitous occurrence of a series of local crises were vital antecedents for the successful implementation process. These studies implicitly highlight the complexities of the context of use and how social dynamics shape the implementation and use of IS. Nonetheless, Leonardi \& Barley (2010) explicitly argue that five perspectives - perception, interpretation, appropriation, enactment, and alignment is a comprehensive approach to explain the social construction of IS implementation. They take these perspectives to explain how social dynamics (i.e. attitudes, beliefs, and values) shape different stages of the IS implementation process i.e. pre- implementation, implementation and postimplementation and the meaning technology has on the various stages.

The studies above are concerned with how organisations and their members make sense of, use and incorporate IS into their structures, processes, and work practices. This highlights why the organisational culture (OC) theory has been applied in IS studies to explain how organisational members enact IS in their everyday work, and why they respond to IS implementation in manners they do i.e. favourable or unfavourable responses (see Koch et al., 2013; Ravishankar et al., 2011). OC can be vital for understanding IS implementation; especially in trying to achieve desirable behaviours during the post-adoptive and acceptance stages of IS because the activities in these implementation stages are distinct from each other. Therefore, users' interactions with an IS in the different implementation stages (Cooper \& Zmud, 1990) may result in users having different interpretations and attitudes when interacting with the system during the implementation process. Against this backdrop, our study proposes that OC theory can be helpful in providing deeper insights into the dynamic activities that ensue during IS implementation.

\section{ORGANISATIONAL CULTURE AND IS IMPLEMENTATION}

Researchers have taken different paradigms to define the concept of organisational culture (OC). Two main distinct paradigms of $\mathrm{OC}$ are the functionalist and the interpretivist paradigms.

The functional studies of OC suggest culture as something an organisation possesses based on agreed assumptions, beliefs, and practices (Smircich, 1983). Furthermore, Smircich (1983) argued that studies that take the functionalist paradigm to OC treat culture as a variable to create a link with other variables such as commitment and productivity, so as to offer direction to how culture may impact organisational goals i.e. better productivity and efficiency. Schein (1992) draws from the functionalist perspective to argue that culture exists at three levels (assumptions/beliefs, values/norms and artefacts). He further claims that among the three levels, espoused values are more visible, and members are more aware of them.

Alavi et al. (2006) adopt Schein's (1992) perspective of cultural values to investigate how OC influences the use of knowledge management systems (KMS) to achieve successful knowledge management $(\mathrm{KM})$ practices. They report that there are discoverable relationships between organisational values and members' behaviors on IS use. For example, the argue that values such as embracing collaboration significantly facilitated members' use of KM tools for sharing of tacit knowledge, engendering natural infusion of new members into the organisation. Also, Iivari \& Huisman (2007) adopts Schein's (1992) conceptualization of OC to develop a research model to analyze the 
relationship between OC and the deployment of systems-development methodologies. Their results highlight that IS developers' deployment of methodologies is widely linked to hierarchical cultural values that are oriented towards security, order, and routinization. A further significant finding from the study is that IS managers' critical attitudes of the deployment of methodologies in organisations are influenced by values such as productivity, efficiency, and goal achievement; that is, a strong rational culture.

Iivari \& Iivari (2011) extended on Iivari \& Huisman's (2007) work by promoting Quinn \& Rohrbaugh's (1983) value typology to assess the relationship between OC and the deployment of agile methods. They argued that a strong organisational hierarchical culture facilitates the mandatory implementation of agile systems-development methods, while a high developmental culture makes organisations dysfunctional if a more formalised agile approach is taken. Iivari \& Iivari's (2011) suggestion of the relationships between OC and agile system-development methods echoes the functionalist perspective of OC that culture should be treated as a variable to create a link between culture and other variables so as to offer standard direction to how culture may be managed to ensure organisational success.

The interpretivist paradigm argues that organisations are cultures and treats culture as a metaphor for organisational life (Meyerson \& Martin, 1987; Smircich, 1983). In this view, culture is seen as an interpretive tool to allow the investigation of organisations as a social phenomenon and OC may not be managed in an integrative way. Martin (1992) echoes this point by suggesting that organisations consist of groups that are multiple, often oppose one another, and have ambiguous cultural identities. Thus, Martin $(1992,2002)$ suggests that OC should be studied from three different perspectives integration, differentiation, and fragmentation.

The integration perspective of $\mathrm{OC}$ assumes that the organisation has a consistent culture across all subgroups, and members share the underlying assumptions, value symbols, and ritualised practices (Martin, 2002). All members of the social system have the same interpretations of cultural manifestations, and view explanations of processes in the same way (Schein, 2004). In this view, members share a common perspective on where the organisation is heading and are fully in tune with the underlying assumptions, beliefs and practices. Differentiation studies focus on variations within a group, the unavoidable influence of power, and conflicts of interest, which leads to a differentiated culture (Pfeffer, 1981). The differentiation perspective of OC, unlike the integration perspective, assumes that organisations are composed of overlapping, nested subgroups with particular cultural manifestations, i.e. subcultures that coexist in relationships that may be in harmony, conflict or indifferent to one another (Martin \& Siehl, 1983). The fragmentation perspective highlights ambiguity as the core of culture (Martin, 2002). The paradigm of the fragmented perspective argues that culture shared in an organisation will differ across organisational groups (Louis, 1985), implying that culture can be as much a fragmenting force as a unifying one (Van Maanen \& Barley, 1985). Although organisational members believe that they belong to a single OC, they do not seem to "agree on clear boundaries, cannot identify shared solutions, and do not reconcile contradictory beliefs and multiple identities" (Meyerson, 1991 p. 254-270).

Many IS scholars have adopted Martin's $(1992,2002)$ perspectives of OC to obtain a richer understanding of culture and the use of IS in organisations (e.g. Dubé \& Robey's, 1999; Jackson, 2011; Rivard et al., 2011). These aforementioned studies interpret that the dynamics of IS implementation activities are shaped by the conflicting and ambiguous interests of different user groups in organisations, creating user resistance to the organisational change embodied in the IS. In particular, the work of Rivard et al. (2011) adopts Martin's (1992) three perspectives of OC to investigate, at the organisational and subgroup levels, the antecedents of implementing clinical information systems (CIS). They identify four values - quality of care, and efficiency, of clinical practices (integration perspective analysis), professional status/autonomy and medical dominance (differentiation perspective analysis), which play vital roles in CIS implementation in hospitals. Their analysis from the fragmentation perspective reveals that hospital stakeholders occasionally 
have ambiguous understandings of either some CIS characteristics and/or implementation practices in terms of their consistency with the existing four central values. Similarly, Jackson (2011) adopts Martin's conceptualisation of OC to investigate the adoption and implementation of a virtual learning environment (VLE) in further- and higher-education establishments in the UK. His findings suggest that the organisations' VLE implementation failures were due to the conflicts, inconsistencies and ambiguities that arose during the implementation process.

The above-mentioned authors have subjectively imposed each of the cultural perspectives as an interpretive framework to investigate their research problem. Thus, there is an advantage to using multiple perspectives of OC because multiple lenses highlight relations between different organisational viewpoints, as opposed to the singular-lens approach characterised in most IS-OC studies (e.g. Alavi et al., 2006; Huang et al., 2003; Iivari \& Iivari, 2011). The use of multiple lenses helps reduce theoretical blind spots related to a single perspective and allow the emergence of a more holistic understanding of the cultural dimensions of organisations (Martin, 2002).

The above examples of the application of OC in IS research highlight that OC shapes the way that groups would appreciate a new system. These IS-culture studies suggest that conflicting outcomes of IS implementations should be expected, rather than seen as an anomaly. Thus, the shared culture of a collective would determine the interpretations of the system and subsequently influence usage. This social shaping concept suggests that cultural groups' view IS as symbolic (Kaarst-Brown \& Robey, 1999; Robey \& Boudreau, 1999), i.e. IS will symbolise different values to different user groups.

Despite adopting Martin's (1992) OC perspectives as theoretical lenses for our study, in the attempt to predict and measure the complex concept of OC, Schein's (1985) definition of values is chosen for our study to conceptualise OC and subcultures. Organisational values are easier to study compare to underlying assumptions/beliefs, which are invisible and preconscious (Alavi et al., 2006; Leidner \& Kayworth, 2006). This is appropriate as values are reflections of underlying cultural assumptions (Schein, 1992) and because there is evidence of a strong linkage between cultural values and subsequent behaviour and actions of social groups (Posner \& Munson, 1979). Applying the organisational values concept to the IS context suggests that values of an organisation would influence the implementation of an IS (Alavi et al., 2006).

While the reviewed IS-culture studies are relevant to IS research, they do not provide sufficient insight into how OC could explain the achievement of an IS outcome. Instead, they focus on how ISs are enacted in particular cultural contexts from the cultural members' perspective to show how members manifest multiple and inconsistent interpretations of an IS, based on their different cultures. Our study adds to the IS-culture studies by exploring the implication possible salient cultural practices may have on the outcome of IS implementation by examining organisation-wide factors as well as nuances from subcultures using integration and differentiation model of analysis. None of the existing IS-culture studies has taken this approach (Rivard et al., 2011). We envisage that taking this approach will enable us to better explore the complexity and multi-dimensionality of members' actions during the IS implementation process, so as to better understand why IS implementations fail.

\section{METHODOLOGY}

We conducted an in-depth case study of a large, global Nigerian bank in order to understand the influence of organisational subcultures on the implementation outcome of a management information system (MIS). The case study strategy is beneficial because it enables the study of IS in its natural setting to obtain an understanding of the nature and complexity of the processes involving the IS artefact (Benbasat, Goldstein, \& Mead, 1987). Using the case study approach, we adopt the "soft positivism" research philosophy, which provides the opportunity to reveal pre-existing phenomena and relationships among them (Kirsch, 2004). In our case, it allowed us to conduct the data analysis with certain expectations based on prior theory, but also to obtain some unexpected findings and 
explanations from our data, in the manner of the interpretivist approach (Ravishankar et al., 2011). We discuss our case study approach below.

\section{Motivating Assumptions}

Similar to the procedure of Ravishankar et al. (2011), we conducted our fieldwork at Alpha Bank, with a premise that organisational subcultures exist, influence the outcome of MIS implementation, and are identifiable using an existing theoretical lens. This position captures the positivism inherent in our study. Accordingly, our study draws on Martin's (2002) integration and differentiation perspectives of organisational subcultures to objectively analyse the MIS implementation process in Alpha Bank. Nonetheless, we were open to the interpretivist position during the interviews, which allowed informants to describe, in their own words, their experiences and views of working in a group, and in the organisation as a whole, thereby highlighting the subcultures and OC, respectively. This enabled us to explore questions on what Alpha Bank members generally thought about the MIS, and how it related to their values and priorities. Further, using the subjective mode of analysis helped us to identify themes that explain the degree of influence (i.e. saliency) of members' cultural practices on the MIS implementation, providing a deeper understanding of the IS implementation phenomenon.

\section{Case Access and Data Collection}

The case study focuses on a Nigerian Bank, Alpha Bank (a pseudonym), which operates in the main financial centres including London, New York, and Paris. The research focus guided the selection of the case study site; consequently, we selected Alpha Bank as it had recently implemented a robust enterprise MIS, and showed evidence of members manifesting different interpretations of the system. This provided an opportunity to understand the implementation of an IS from the OC perspective. The first author conducted intensive fieldwork at Alpha Bank in the form of 62 semi-structured interviews with 47 key informants in the bank's headquarters in Lagos, Nigeria (see Table 1).

The interviews used a snowball approach (Patton, 2002) based on members' recommendations when asked: "Which other senior members use the MIS system?". The interviewees were from the Finance, Information Technology (IT) and Operations groups of the bank. We tape-recorded and transcribed 59 interviews. Three interviewees refused to be tape-recorded; therefore, recording of these interviews involved taking notes and expanding these into field notes immediately after the interviews.

An interview schedule was developed based on existing literature on organisational culture and organisational implementation of IS. To understand Alpha bank members' perceptions of the MIS and how it related to their values, assumptions, and priorities, informants were asked to provide examples of how the values they subscribed to at the organisational and subgroup levels influenced their interactions with, and usage of, the system, and the implementation outcome. For example, informants were asked to discuss and describe the components of the values they subscribed at the organisational and their subgroup levels. Informants were invited to explain if they thought their subgroup had distinctiveness regarding organisational culture that made it different or similar to the organisation as a whole. Further, they were asked how Alpha bank's culture as a whole and their subgroup's subculture impacted the implementation of the MIS. We cross-referenced the informants'

Table 1. Summary of interviews and interviewees' positions at Alpha Bank

\begin{tabular}{|l|c|c|c|c|}
\hline \multicolumn{1}{|c|}{ Group } & Senior-level managers & Middle-level managers & Low-level managers & Total \\
\hline Finance & 6 & 17 & 7 & 30 \\
\hline Information Technology & 5 & 5 & 3 & 13 \\
\hline Operations & 4 & 8 & 7 & 19 \\
\hline Total & 15 & 30 & 17 & 62 \\
\hline
\end{tabular}


claims with many other participants that also made similar claims. The interviews were supplemented with unobtrusive observations of members in their settings, and, in some instances, observations of members in their interactions with the MIS. Formal documents in the form of the business case for the MIS, and memos and e-mail correspondence regarding policies for the use of the MIS, were used as multiple sources of evidence and for triangulation purposes, providing validity to the study (Yin, 2009). The research data was collected over a seven-month period.

\section{Data Analysis}

The data analysis followed the three concurrent activities identified by Miles \& Huberman's (1994): data reduction, data display, and conclusion drawing/verification. The data reduction stage involved carefully reading all the interview transcripts and field notes several times to interpret and code the informants' perceptions of Alpha Bank's culture (at the organisational and subgroup levels), and the resulting implications of their interactions with the MIS. We coded based on similar statements that best described the informants' views, attitudes and relationship with the MIS during the implementation process from the perspectives of Alpha Bank's OC (integration) and subcultures (differentiation). We created five coding categories: "implementation process," "Alpha Bank's organisational culture," Alpha Bank's subcultures," "implication of Alpha Bank's organisational culture on the implementation outcome," and "implication of Alpha Bank's subcultures on the implementation outcome." Also, while coding each interview transcript, the degree of influence (saliency) of members' cultural practices on the implementation of the IS was determined by rating particular employee actions and behaviours as highly significant, significant, less significant and insignificant, as revealed from the collected data. We applied ratings by reading transcripts. Informants' indications that organisational/subgroup values had highly significant, or significant impacts on the way they engaged with the MIS and we coded the implementation outcome as salient. We coded informants' suggestions that organisational/ subgroup values had a less significant or insignificant bearing on their engagements with the MIS and the implementation outcome as latent. The resulting set of categories and codes are listed in Table 2.

The three authors were involved in the data coding, but the authors independently reviewed the coding scheme and subsequently discussing coding decisions to reach an agreement. These ensured data interpretations were accurate and to avoid coding bias. The second stage of the data analysis involved displaying the data in matrix format. This included creating a series of conceptually ordered displays to study the themes in more depth. The matrix summarises each of the different aspects of the two broad theoretical lenses (integration and differentiation perspectives of $O C$ ) on the explored phenomenon (IS implementation outcome) (see Table 3 in the Discussion section). This helped to generate more explanatory power to facilitate the drawing of valid conclusions from the findings in the final stage of the analysis. Upon completion of the second stage of data analysis, we conducted a conclusion/verification stage. The goal was to identify common, unique and causal features in the

Table 2. Categories and codes for organisational culture construct

\begin{tabular}{|l|l|}
\hline \multicolumn{1}{|c|}{ Category } & \multicolumn{1}{c|}{ Example Codes } \\
\hline Implementation process & $\begin{array}{l}\text { Design and development of the MIS (pre-implementation), members' } \\
\text { participation, use (implementation) and extended use of the MIS (post- } \\
\text { implementation) }\end{array}$ \\
\hline Alpha Bank's organisational culture & Alpha Bank's organisation-wide interpretations, values, and behaviours \\
\hline Alpha Bank's subcultures & IT, finance, and operations groups' interpretations, values and behaviours \\
\hline $\begin{array}{l}\text { Implication of Alpha Bank's organisational } \\
\text { culture on the implementation outcome }\end{array}$ & Salient, latent \\
\hline $\begin{array}{l}\text { Implication of Alpha Bank's subcultures on } \\
\text { the implementation outcome }\end{array}$ & Salient, latent \\
\hline
\end{tabular}


Table 3. MIS implementation from the integration and differentiation perspectives of organisational culture

\begin{tabular}{|c|c|c|c|c|c|c|}
\hline & \multicolumn{6}{|c|}{ Implementation Stages } \\
\hline & \multicolumn{2}{|c|}{ Pre- Implementation } & \multicolumn{2}{|c|}{ Implementation } & \multicolumn{2}{|c|}{ Post-Implementation } \\
\hline & Interpretation & Behaviour & Interpretation & Behaviour & Interpretation & Behaviour \\
\hline $\begin{array}{l}\text { Organisation- } \\
\text { wide culture }\end{array}$ & $\begin{array}{l}\text { Members' } \\
\text { interpretations } \\
\text { of design and } \\
\text { integration of } \\
\text { the MIS into the } \\
\text { existing bank's } \\
\text { legacy systems } \\
\text { facilitated by the } \\
\text { organisation- } \\
\text { wide value of } \\
\text { resilience. }\end{array}$ & \multirow[t]{2}{*}{$\begin{array}{l}\text { Members } \\
\text { showed } \\
\text { resilience } \\
\text { ("can do" } \\
\text { attitude) } \\
\text { when faced } \\
\text { with design } \\
\text { challenges } \\
\text { of the MIS. }\end{array}$} & $\begin{array}{l}\text { Members' } \\
\text { interpretations } \\
\text { of the MIS use, } \\
\text { facilitated by the } \\
\text { organisation- } \\
\text { wide value } \\
\text { (resilience). }\end{array}$ & \multirow[t]{2}{*}{$\begin{array}{l}\text { Accepted } \\
\text { use of the } \\
\text { system. }\end{array}$} & $\begin{array}{l}\text { Members' saw } \\
\text { the MIS as } \\
\text { commonplace. }\end{array}$ & \multirow[t]{2}{*}{$\begin{array}{l}\text { Members } \\
\text { were able to } \\
\text { use the MIS } \\
\text { effectively. }\end{array}$} \\
\hline $\begin{array}{l}\text { Level of } \\
\text { influence }\end{array}$ & High ++++ & & Moderate +++ & & Low ++ & \\
\hline Subcultures & $\begin{array}{l}\text { Finance group } \\
\text { members } \\
\text { uncomfortable } \\
\text { integrating the } \\
\text { MIS into their } \\
\text { processes due to } \\
\text { their accuracy- } \\
\text { driven sub-value. }\end{array}$ & \multirow{2}{*}{$\begin{array}{l}\text { The IT } \\
\text { group's } \\
\text { conflicts } \\
\text { with some } \\
\text { finance } \\
\text { group } \\
\text { members' } \\
\text { slightly } \\
\text { hindered the } \\
\text { adaptation } \\
\text { and } \\
\text { integration } \\
\text { of the MIS } \\
\text { into Alpha } \\
\text { Bank. }\end{array}$} & $\begin{array}{l}\text { Subgroups' } \\
\text { interpretations } \\
\text { of the MIS } \\
\text { use were } \\
\text { inconsistent } \\
\text { with their } \\
\text { accuracy- and } \\
\text { superstar-driven } \\
\text { sub-values. }\end{array}$ & \multirow[t]{2}{*}{$\begin{array}{l}\text { Many } \\
\text { finance and } \\
\text { operations } \\
\text { group } \\
\text { members } \\
\text { refused } \\
\text { to use the } \\
\text { MIS. }\end{array}$} & $\begin{array}{l}\text { Differing } \\
\text { interpretations } \\
\text { between the } \\
\text { subgroups } \\
\text { that the MIS } \\
\text { could be used } \\
\text { effectively to } \\
\text { produce accurate } \\
\text { results and } \\
\text { perform dynamic } \\
\text { analysis. }\end{array}$ & \multirow[t]{2}{*}{$\begin{array}{l}\text { Many } \\
\text { members } \\
\text { found it } \\
\text { difficult to } \\
\text { use the MIS } \\
\text { as a regular } \\
\text { daily tool. }\end{array}$} \\
\hline $\begin{array}{l}\text { Level of } \\
\text { influence }\end{array}$ & Low + & & High ++++ & & $\begin{array}{l}\text { Very High } \\
+++++\end{array}$ & \\
\hline
\end{tabular}

data that would present fresh insights into the different interactive processes that occurred during the IS implementation process. To facilitate this procedure, the literature was revisited to synthesise our findings with existing studies. This synthesis helped us to develop our theoretical insights (see Pan $\&$ Tan, 2011) into the impact of organisational/subcultural values on IS implementation outcome.

\section{Case Description}

The studied MIS is a three-tiered software architecture that was developed internally to speed up the process of complex data analysis to generate sophisticated management information and reports to facilitate timely strategic decisions. Some members of the finance and operation groups worked with the IT group to ensure that the specific functional requirements of the different departments were accommodated in the MIS. The introduction of the MIS was born of necessity, intended to replace outdated and manual methods of performing organisational tasks, such as relying on Excel spreadsheets and existing legacy systems. Before the implementation of the MIS, user acceptance tests were conducted. After the completion of these tests, the system was introduced to members through a range of promotional campaigns to raise awareness of the new system and training sessions. Alpha Bank expected all members who had participated in the training sessions to use the MIS for their daily organisational tasks. 


\section{FINDINGS}

This section reports the findings concerning how saliencies of organisational subcultures in Alpha Bank impacted the implementation outcome of its MIS.

Analysing the data from the integration perspective of OC revealed some shared interpretations, experiences, beliefs and values that were clear and consistent among members across the bank. In particular, informants at Alpha Bank talked about their subscription to the bank's core value of resilience. Members of the bank are expected to think, communicate and be persistent when they face challenges in tasks assigned to them. This attitude is considered an essential ingredient in the way assignments are executed at Alpha Bank, with members required to embrace tasks regardless of the scale of the challenge presented. This attitude of "nothing is impossible" was identified as a defining feature of the bank's recovery from an ailing organisation in 2005, to currently one of the top three banks in West Africa. The shared nature of the resilience value suggests that members believed that they were united in their attitudes and responses to any challenges and issues faced when completing their work tasks.

Nonetheless, analysing the data from the differentiation perspective of OC revealed that the finance, IT, and operations groups had their distinct subcultures. The core characteristic of the finance group's subculture was their emphasis on accuracy in every task undertaken by the group. The group members believed that their standards of accuracy were higher than other parts of the bank and that their work outputs were the most thorough. The IT group perceived themselves as doing things in practical and technical ways to attain organisational effectiveness; i.e. they manifested a "pragmatic"-driven subculture. The operations group responsible for the re-engineering of any and all of the business groups/subsidiaries in Alpha Bank felt that they were the engine of the bank's progress and consequently had an ego-driven attitude. They manifested a "superstar" culture, and had an air of arrogance, feeling that they should have been given the discretion to select which methods or processes to adopt in achieving their tasks. These identified organisational subcultures were the only cultures many of the informants consistently spoke about when asked about the values they subscribed to at the organisational and subgroup levels and appeared to be consistent with Martin's $(1992,2002)$ classification of OC. The results section, below, examines how Alpha Bank's OC (integration and differentiation) influenced implementation of the MIS.

\section{Impact of Organisation-Wide Value (Resilience) on the Implementation Outcome}

The data showed that when Alpha Bank began to develop and install the MIS, the bank's core value of resilience had a positive impact on the adaptation of the MIS into its organisational setting. Members identified a number of examples in which their resilience to problems and challenges during the early stages of the MIS project ensured that progress continued. These attitudes were demonstrated through problems being directly addressed and members working hard to meet deadlines. This required additional meetings and considerable time demands on both teams, but their shared desire to overcome the challenge helped to facilitate the functional changes to be made. One informant made the following observations:

The way they [the MIS IT team] are doing things, they have exhibited the value of the bank, being resilient, at times you want to design a template in the MIS for report generation and the MIS [IT] team's timelines are tight but this report is crucial ... so they are spirited in their efforts to make sure that you get [a] report to meet your deadline, even when we had not provided our requirements for the MIS at the time they had stipulated. They more or less [embody] the resilient culture of the bank.” Business Operations Support (operations group) 
There were also situations in which, although the standard functionality of the MIS represented a reduction in quality compared to the legacy systems, the finance and IT group members were determined to work together to resolve the problems and recreate the necessary report outputs.

At the initial stage of trying to develop the MIS, it was very tough for the IT team and us ... because some of our processes were not enhanced within the MIS. We did not have [the] ability to store some data ... but we showed resilience, we kept on fighting. We kept on trying to align those reports until it was achieved ... it is commendable. Senior Credit Analyst (finance group)

The resilience value helped significantly to support teamwork and collaboration between the different groups (IT, finance and operations) when capturing the requirements of the MIS, and designing required non-standard functionality to adapt the new system into Alpha Bank's organisational settings. When the MIS system was rolled out, the informants commented that their resilient attitudes had helped when they found the MIS difficult to use to complete their organisational tasks, such as when the system returned inaccurate data or reports:

The resilience culture applies because, as an example, we had challenges in using the system effectively in our unit. Because we had the 'can do it' attitude, it made us resilient, and we kept trying till we got it right. This resilience culture ... has made the use of MAXIM enjoyable to us now. Head of Risk Management (finance group)

Similar attitudes were also reported within the Operation Group. For example, one manager remarked:

The IT Group like every other group in the bank is resilient in their ways, they tend to bend [over] backwards to make sure that users are comfortable with their systems, especially the MIS, which helped us to engage with it. Business Operations Support (operations group)

The positive behaviour towards the MIS due to the shared resilience value encouraged members to overcome the challenges and issues faced when using the MIS for their organisational work. This positive behaviour ("can-do" approach to problem solving) made members use the MIS effectively, which had a positive influence on the implementation process.

The data also indicated that subcultural differences in the bank also had an impact on the implementation of the system into the organisation. This resulted in the lack of engagement with and user resistance to the new system, with many members engaging and using the MIS as little as possible. This is discussed in the subsequent section.

\section{Impact of Subcultural (Accuracy- and Superstar-Driven) Values on the Implementation Outcome}

During the early implementation activities, there was some evidence of conflicts between the IT and finance group when configuring modules for the MIS. The battles occurred during the design stage concerning the type of functionality that the MIS could support. For example, some finance group members were cautious about adopting the MIS, as they were suspicious of the quality of the system and the level of accuracy that it could support. This suggests that the finance group's subcultural assumptions of accuracy influenced the speed with which they adopted the new system.

We had problems in integrating the MIS into our work processes, because of the sensitivity involved in our work and getting the account/figures right. We have a specific format, financial statistics, designed by the Central Bank that must be followed, so we needed to map all the general ledgers 
to align with that. So we [did not] trust the MIS to be integrated into our systems. Senior Financial Analyst (finance group)

Similar disagreements also ensued between the IT Group and the Operations Group during the development of MAXIM. In this example, there was some confusion between the different groups with the reports that were being generated from the system not meeting the needs of the Operations team. This required several attempts to create reports that were useful to the operations team and this delay, and lack of availability of information was thought to be hindering the effective performance of the group. An informant commented,

When they (MAXIM IT Team) did the query, it wasn't what we wanted, so we went back and forth, it was difficult, and it was affecting performance. Business Operations Support (operations group)

The above comments indicate that some members did not have common perceptions regarding how they could adapt the MIS for their organisational use. In many ways, this is in line with Wagner \& Newell's (2004) suggestion that differentiation between teams' sets back IS implementation. However, during this pre-implementation stage i.e. design, development and adaptation of the MIS into the bank's settings, the wider consensus among the informants was that the bank's resilience value impacted positively on the development of the MIS, providing a positive force to continue the MIS implementation into Alpha Bank's organisational setting. In other words, the organisation-wide value of resilience was more salient than the finance subcultural value of accuracy.

Upon introducing the system for organisational use, the finance group members continued to question whether the utilization of the MIS was consistent with the group's accuracy-driven culture. Informants explained that they were unsure that the system would generate the information required for the finance group to produce accurate reports for senior management and regulatory bodies. Several group members commented that they were more comfortable with, and had more confidence in, their established methods of working, and had been unwilling to engage with the new system:

There was resistance when the MIS was introduced mainly because people didn't know the system, so we did not trust it or the figures generated from it. We had to be careful we didn't send inaccurate information to top management or regulatory bodies because of the use of the MIS, so we used the old manual system instead that we were familiar with. Head of Balance Sheet and Market Risk Management (finance group)

The mistrust of the new MIS was compounded by some negative experiences when attempting to use it. For example, informants reported that they found that the system did not have the expected levels of functionality. They suggested the MIS produced inaccurate or incomplete data or was not configured to fit with the requirements of the finance groups' calculations:

We noticed that there are some things that are so basic that you thought [the] MIS would do and you just noticed it is not working as expected ... [such as] errors and omissions in the figures; you will be disappointed ... so you can't use the system.” Head of Financial Subsidiaries (finance group)

Thus, the finance group was reluctant to adopt the MIS because it did not allow them to achieve levels of reliability and accuracy that were seen as core values for their group. The informants in the operations group reported similar experiences, explaining that their department was less formal and structured in the way they completed tasks compared to other departments. The operations group felt they had discretion to decide which method or processes to adopt, including the use of an IS to 
maximise their outputs and achieve target levels of performance. Thus, they felt the introduction of the MIS undermined their discretional approach:

Well, delivery is important to us, so discretion is allowed to come into play, even in the use of IS. We cannot do otherwise because ... we keep getting deadlines for this, and that from management passed down to us every day, so we like to get the job done in our preferred methods. That is how we work and get the job done. The use of the MIS was not allowing us discretion, [so] we did not use it. Cards Administrator (operations group)

Thus, during the implementation stage (system roll out for organisational use), the subcultural differences began to have a greater influence on the implementation process. The differentiated subcultures were more salient compared to the integrated organisation-wide value of resilience.

After introducing the MIS to users, senior management expected members to continue to use the system on a routine basis (i.e. post-implementation). However, in practice, many members rarely used the MIS as the lack of engagement and user resistance to the system that had started since its rollout had increased. The organisation-wide value of resilience (integration) was becoming very latent due to the growing saliency of the subcultural effects (differentiation). This was evident in comments from informants in both the finance and operations groups. The finance group, who were highly concerned with "accuracy efficiency," chose to run the MIS in parallel with their existing systems and methods so that they had a trusted alternative if any doubts arose over the reliability of the data from the MIS. This also enabled them to continue using their preferred established techniques and reduced the need to rely on the new system. Therefore, there was little evidence from this group that they considered the use of the MIS as a normal and everyday occurrence. One informant explained:

The use of the MIS was running in parallel with our existing methods of financial analysis ... this may have affected our use of the MIS and the failure of the project, but the accuracy of our work is more vital to us, and that can only be guaranteed by the use of the methods we are already comfortable with. Head of Risk Management (finance group)

As well as doubting the reliability of the information from the MIS, finance group members also expressed concerns about the speed at which the IT group had attempted to implement the new system. The finance group had been keen to conduct multiple replication tests of the system to confirm that it was producing the same results as their existing methods. However, the IT group pragmatically felt that this would have represented an excessive testing routine and delayed the project unnecessarily. A member of the IT group explained:

Due to the finance [group's] value of accuracy, there was friction when initial concerns over the accuracy of the reports arose. Naturally, in any project, the bringer of change needs to give a case for what value the change brings. ... finance wanted first to see a replication of what was on the ground before seeking improvements, whereas IT, because of efficiency, would want to skip the middle stage and go straight to improvements. That is where the conflicts arose, and it discouraged finance from using the MIS in effective ways, leading to the failure of the system. Database Administrator (IT group)

Informants in the operations group made similar observations. They had different perceptions of the MIS capabilities and felt it was not easy to use. Many in this group only used the MIS for data extraction purposes and used the more familiar Microsoft Excel software for data analysis. These members decided not to rely on the MIS, feeling that the MIS alone would not enable them to achieve effectiveness in their work, and thus combined its use with other methods, highlighting the group's preference for a discretionary approach. One senior manager explained: 
I may be able to do analysis in the MIS but for my performance, I prefer to export generated data from the MIS to Excel for analysis because it is quicker, so I don't really use the new MIS. Head of Operational Control (operations group)

This attitude of the operations group caused conflict with the IT group. The operations group stated that sole use of the MIS was not quick enough; however, the IT team argued against this. A senior programmer explained:

The data for all calculations and analysis are in the MIS. It can be extracted. Just because it ... hasn't been requested doesn't mean it isn't doable. I am sure if it is requested, we can give them what they want, rather than causing the failure of the project. Senior Programmer (IT group)

This non-routine usage resulted in the failure of the implemented MIS because members did not use the system in a way that could achieve the organisational goal of speeding up the process of complex data analysis to generate sophisticated management information for timely strategic decisions. The above comments suggest that the problem related not to a lack of functionality, but to a lack of access to the relevant functionality, which the operations group had not requested. The operations group's superstar-driven attitude and preference for their discretionary approach prevented them from fully engaging with the pragmatic IT group (who were practical but reactive) to request traditional tasks to be automated in the MIS. The operations group's ego-driven and superstar mentality may have clouded their view of what constituted a highly useable system. Therefore, it appears that a user-developer gap had emerged concerning required and available functionality, and this was compounding the low levels of engagement with the MIS from the operations group. The conflicts between the IT and operations groups originated from the latter's view that the MIS would not allow them to be effective, and the former's expectations that the MIS could be continuously adapted to meet the expected level of sophistication as long as the operations group made such requests known to them. This breakdown between the different groups is encapsulated in the following comments:

The problem is that people that are sitting on the MIS side, they know only coding, and they don't know what banking is all about. We need somebody who can understand both, [and this is the] reason why the implementation outcome was unfavourable. Head of Card Operations (Operations Group)

The above comments highlight the negative impact the very salient disagreements had on the usage of the MIS, which is consistent with Martin's $(1992,2002)$ differentiation perspective of OC, resulting in the failure of the MIS project. It appears that the new system did not support the finance group's core value of accuracy or the operations group's way of working via discretionary/unconventional methods. These differences and conflicts hindered the communication and interaction between the subgroups when the MIS was implemented and used in a routine manner. These factors prevented the system from being integrated further into the bank and was consequently unbeneficial for the MIS implementation. Similar to findings by Ravishankar et al. (2011) and Rivard et al. (2011), the differences in cultures between the IT and finance/operations groups was the reason for the conflict. These members were not interested in using the system in a routine and comprehensive manner to support higher-level tasks in the organisation.

Our analysis also indicates that although the organisation-wide value of resilience was consistent across the three subgroups, the subgroups existed in relative isolation to one another. The subgroups in the bank operated a "silo mentality" that resulted in their behaviours and views being heavily influenced by their own group's agenda and priorities, as highlighted by the Head of the Operations Group: 
One of the main issues was that people were not just familiar with having such [a high] level of openness, most people were just ... used to seeing what they are doing only in their silos.

A Database Administrator added:

Despite the shared value across the bank, there are routines within each subgroup, [which are] significantly different from the rest, so there are different working practices in each [of] the groups.

This lack of engagement between the subgroups highlights how subcultures can coexist in a conflict-type relationship to one another (Martin \& Siehl, 1983), and the significant impact contrasting cultural traditions can play during IS implementations.

\section{DISCUSSION}

Our case study reveals a clear pattern that the task characteristics in the preceding stage of the MIS implementation had an impact on the subsequent stages. The integrated organisation-wide value of resilience was salient in the pre-implementation stage. The shared resilience among members had a vital positive influence on their commitment to the design and installation of the system. In the pre-implementation stage when the MIS adaptation started, many members of the IT, finance and operation subgroups displayed positive integrative behaviours in handling the issues that arose during the design, development, and installation of the MIS. Because many organisation-wide members interpreted the tasks and activities of the MIS adaptation regarding its consistency with Alpha Bank's value of resilience, a consensus was reached across and within subgroups i.e. Martin's (1992) integration perspective of OC). Alpha Bank's organisation-wide value of resilience may be described as having a high influence on its members' positive behaviour towards successful adaptation of the MIS into the bank's organisational settings. This finding is similar to those of McMaster \& Wastell (2005), which highlight that factors such as commitment of organisational members were important antecedents in the development and deployment of a business process re-engineering system. However, our study shows that even at this early pre-implementation stage there was some evidence of conflicts between the IT and finance groups when configuring modules for the MIS. Their interpretations of the business terms and functionalities differed, leading to disagreement between these subgroups. Despite the evidence of differentiated subcultures engendering resisting behaviours towards the MIS during the pre-implementation stage, the resisting actions were latent most of the time, consequently not hindering the MIS to progress to the implementation stage.

When the MIS was introduced to the wider bank populace for organisational use (implementation stage), the integrated organisation-wide value of resilience became less salient as differentiation across Alpha Bank's subgroups emerged (conflicts and disagreements) and became more salient. Many members in the finance and operations groups interpreted the use of the MIS as inconsistent with their respective subgroup values of accuracy and discretionary approach, causing them to resist the system. The differentiation effects continued, as they were most salient during the postimplementation stage. Very few members used the MIS in a regular way or considered its use as part of their everyday work activities, implying that the integrated organisation-wide value of resilience became very latent. The resistance from the finance and operations groups continued to prevent the system from being assimilated further into the bank. The members were not interested in using the system in a routine way, as their core concerns regarding the reliability of the data produced by the system had not been addressed (finance group) and use of the MIS prevented the use of discretionary processes (operations group). Therefore, the salient differentiation in Alpha Bank led to high levels of user resistance, resulting in the failure of the MIS. The interpretations and behaviours during the MIS implementation are summarised in Table 3. 
The empirical data show how Alpha Bank members' attitudes and behaviours dynamically changed, shaped by the forces that were manifested due to their interactions with the MIS in the implementation stages of the system. The members' manifestations of the organisation-wide value of resilience towards the MIS was most salient in the pre-implementation stage, but latent in the implementation and post-implementation stages, where their "can do" attitude seemed to be less forthcoming. Members should have manifested the resilience value especially in the later stages of the post-implementation process to overcome the complexities and difficulties related to effectively using the MIS. Thus, the subcultural elements took precedence in the implementation stage and grew in saliency in the post-implementation stage. The implementation of an MIS was not the central part of the finance and operation member's jobs - it was thought to support them to complete their tasks and overcome work challenges. Therefore, it is possible that when the members did not consider something to be a particular type of work problem, the manifestation of the resilience value became less necessary and the subcultural values came to the fore. The change in the members' cultural values during their interactions with the MIS contrasts with Schein's (1999) argument that culture is relatively stable and difficult to change. It may be that the organisation-wide value of resilience became latent to the salient subgroups' values because the introduction of the MIS changed their work patterns. For example, the operations group members normally had the discretion to decide on which methods or processes to adopt in their work. Thus, the expectation that the MIS should be the only tool for producing management information was contradictory to the operations group's norm. This description mirrors Leidner \& Kayworth's (2006) explanation of how the introduction of an IS can cause conflict between cultures; i.e. how cultural conflicts are manifested. Ravishankar et al. (2011) also highlight the potential for cultures to change; they identified a "chameleon" subculture during organisational attempts to align an implemented Knowledge Management System with organisational strategy. This "chameleon" subculture did not identify strongly with the organisation's values or their subgroup value; they only adopted the values of the subgroup they were temporarily seconded to; i.e. they changed their subculture to integrate into different subcultures.

Our subcultural analysis explores the multiple meanings of Alpha Bank members in their interactions with the MIS, paying attention to the absence of consensus (and the presence of conflict and power struggle) in the use of the system, engendering an unfavorable outcome for the MIS implementation. This is contrary to the majority of IS implementation/culture studies, which adopt only the integration perspective (e.g. Alavi et al., 2006; Hoffman \& Klepper, 2000; Iivari \& Huisman, 2007). Our findings show that the failure of an IS was largely dependent on decisions made at the subgroup levels. Thus, if IS success was measured by whether or not the new MIS was successfully integrated into the organisation settings, it would have been perceived that the new system was successful due to Alpha bank members' initial display of resilience towards the MIS during the pre-implementation stage. However, in reality, the implementation was a failure due to members' differentiated attitudes toward the MIS during the later stages of the implementation process.

Our study highlights that the different manifestations of the integration and differentiation behaviours, although isolated from each other, each came to the fore with different salience during the MIS implementation. Dubé \& Robey (1999) explain that overlapping manifestations that these different perspectives reveal can evolve in a rather sequential manner. We argue that the saliency of the various cultural practices emerged and shifted over time because as the system progressed from the pre-implementation stage to the implementation and post-implementation stages, members developed a stronger affiliation to their subcultures rather than to the organisation-wide culture. This prevented members to use the MIS in a continuous and enhanced manner. This is similar to Iivari \& Iivari's (2011) and Von Meier's (1999) arguments that cultural members socially reconstruct the meanings and purposes of their activities when they perceive the use of a new system as too complex and challenging. In our study, due to the perceived complexity of the MIS, Alpha Bank members were unable to gain an implicit sense of how to use the system in a routine manner. This led to a situation where they had to restructure their organisational processes, changes that did not match, but rather 
conflicted with many of the members' subgroup values, causing resistance and disengagements with the MIS. Thus, the differentiated subcultures prevailed over the integrated one; that is, the salient subcultural practices stifled the organisation-wide display of resilience.

It is worth pointing out that the organisational subcultures identified in Alpha Bank may also have been catalyzed from outside the organisation; i.e. by the influence of Nigeria's culture at the national level. Hofstede's (1983) taxonomy, which describes national cultures along the dimensions of pragmatism- normative, individualism-collectivism, and masculinity-femininity, could help provide more insights on how these subcultures were manifested in Alpha Bank. Nigeria scores very low (13) on a scale of 100 of the pragmatism-normative dimension, suggesting a normative culture (The Hofstede Centre, 2014). This may explain why the finance (emphasis on accuracy) and operations (superstar attitude) groups were entrenched in their ideas and ways. These respective group members exhibited great respect for their traditions and were consequently unwilling to adapt to the implemented MIS. On the individualism-collectivism dimension, Nigeria scores 30, meaning it is a collectivistic-oriented society, that is, long-term commitment to the member "group" is key, and overrides external rules and regulations (The Hofstede Centre, 2014). This may also explain why the subcultures were relative isolated, and group members were hesitant to change their practices when the MIS was implemented. Finally, for the masculinity-femininity dimension, Nigeria scores 60 , highlighting a competitive society in which conflicts are typically resolved by fighting them out (The Hofstede Centre, 2014). This may explain the sharp disagreements and battles between the IT group and the finance/operations groups during the MIS implementation process. Therefore, our case, a global bank with several foreign members, highlight that there may still be a strong link between domestic national cultures and deep-seated shared cultural assumptions at the subgroup level. Thus our findings provide insights into how global organisations based in countries similar to Nigeria could manage IS implementations. For example, China (66), India (56) and Saudi Arabia (60) have similar masculinity-femininity dimension scores to Nigeria's 60. Also, China (25), Russia (39) and Saudi Arabia (30) have similar individualism-collectivism dimension scores to Nigeria's score of 30.

\section{CONCLUSION}

Our adoption of the dual perspectives of OC (i.e. integration and differentiation, as posited by Martin 1992, 2002) provided an interpretive lens to guide the analysis of MIS implementation from the OC perspective. It also provided a rich account of how agreements and disagreements that arise during members' interactions and use of an MIS can influence the implementation outcome of the system. Thus, our paper provides clear insights on how differences and conflicts between subculture groups hindered the successful implementation of an MIS. The results enhance our understanding of IS implementation research from the dual perspective of OC, an aspect that has received limited attention in the IS implementation/OC literature (Leidner \& Kayworth, 2006). The contributions of our paper are as follows.

Firstly, our study of IS implementation suggests that increased saliency of members' subscription to an organisation-wide value facilitated the successful adaptation of the IS (pre-implementation stage). But in subsequent stages (implementation and pre-implementation), an increase in saliency of the subcultural values resulted in members' resisting the system, leading to its failure. This provides fresh insights on how salient subcultural practices can lead to IS failures despite the existence of a strong organisation-wide value. This helps answer our research question: How do salient organisationwide and subgroup values influence the outcome of IS implementation? Also, it answers the call to explore the impact the saliency of a given cultural perspective may have on the outcome of an IS implementation (Rivard et al., 2011).

Secondly, our study builds on and contrasts with the vast body of literature that has adopted social cognitive theories to explain IS implementations in organisations. For example, the Unified Theory of Acceptance and Use of Technology and Theory of Planned Behaviour developed by Venkatesh et al. 
(2003) and Ajzen (1991), respectively. These theories serve as antecedents for explaining the use and implementation of technological innovations. They assume that manifested behaviours and practices that come into play during interactions with a technological innovation are quite stable during the implementation process (Leidner, 2010). Our adoption of OC from the integration and differentiation perspectives further our understanding of social cognitive models by highlighting how and why members' interpretations and behaviours towards an IS may change during the implementation process.

Finally, our study makes a significant contribution to practice by demonstrating the need for IS practitioners to appreciate cultural variations across subgroups, as these differences may have a major influence on the usage and subsequent implementation of an IS. A more proactive approach should be taken to alter the salient negative cultural practices that can cause IS failures into more positive organisation-wide practices during the development and use of a new IS to achieve successful implementation; this will increase organisations' likelihood of getting the best return on IS investments.

We acknowledge four limitations of our in-depth study. Firstly, the study was unable to adopt the fragmentation perspective of $\mathrm{OC}$ as a further theoretical lens to explore the implementation process of the MIS. Taking this perspective may have allowed us to capture the ambiguities members faced in the daily use of a sophisticated IS, and improve understanding of the role of OC in IS implementation outcomes. Therefore, further studies could adopt the three perspectives to help provide richer insights into IS implementations. Secondly, future research could explore the deeper role of the IS artefact during the implementation process. IS artefacts have their objective properties and behaviours (Orlikowski \& Iacono, 2001), to provide fresh insights into the nature of the relationship they have with the actors and the organisational tasks during the implementation process. Thirdly, our study was unable to determine whether the subgroups exhibited the same level of influence or one was more dominant and if it had an impact on the implementation process. Hence, further study could explore these. Fourthly, to gain more insights, on the link between domestic national culture and subcultures, future research needs to examine relevant culture dimensions such as pragmatism- normative, individualism-collectivism, and masculinity-femininity and explore their moderating role during IS implementations. Finally, because our study was built upon a single case, we cannot generalise the results to a wider sample. However, we argue that the empirical results from an in-depth single case study provides deep insights and increases the representativeness of the views of the informants regarding IS implementations. Therefore, we can generalise from empirical statements to theoretical statements, i.e. analytical generalisability (Lee \& Baskerville, 2003; Yin, 2009).

\section{REFERENCES}

Ajzen, I. (1991). The Theory of Planned Behaviour. Organizational Behavior and Human Decision Processes, 50(2), 179-211. doi:10.1016/0749-5978(91)90020-T

Alavi, M., Kayworth, T., \& Leidner, D. (2006). An Empirical Examination of the Influence of Organizational Culture on Knowledge Management Practices. Journal of Management Information Systems, 22(3), $191-224$. doi:10.2753/MIS0742-1222220307

Bagayogo, F. F., Lapointe, L., \& Bassellier, G. (2014). Enhanced use of IT: A new perspective on post-adoption. Journal of the Association for Information Systems, 15(7), 361-387.

Benbasat, I., Goldstein, D., \& Mead, M. (1987). The Case Study Research Strategy in Studies of Information Systems. Management Information Systems Quarterly, 11(3), 369-386. doi:10.2307/248684

Burton-Jones, A., \& Grange, C. (2012). From use to effective use: A representation theory perspective. Information Systems Research, 24(3), 632-658. doi:10.1287/isre.1120.0444

Cooper, R., \& Zmud, R. (1990). Information Technology Implementation Research: A Technological Diffusion Approach. Management Science, 36(2), 123-139. doi:10.1287/mnsc.36.2.123 
Dubé, L., \& Robey, D. (1999). Software stories: Three Cultural Perspectives on the Organizational Context of Software Development Practices. Information and Organization, 9(4), 223-259.

Gallivan, M., \& Srite, M. (2005). Information Technology and Culture: Merging Fragmentary and Holistic Perspectives of Culture. Information and Organization, 15(4), 295-338. doi:10.1016/j.infoandorg.2005.02.005

Hoffman, N., \& Klepper, R. (2000). Assimilating New Technologies: The role Organizational Culture. Information Systems Management, 17(3), 36-43. doi:10.1201/1078/43192.17.3.20000601/31239.6

Hofstede, G. (1983). Dimensions of national cultures in fifty countries and three regions. In J. B. Deregowksi, S. Dziurawiec, \& R. C. Annis (Eds.), Expiscations in cross-cultural psychology (pp. 335-355). Lisse, Netherlands: Swets and Zeitlinger.

Huang, J. C., Newell, S., Galliers, R. D., \& Pan, S. (2003). Dangerous Liaisons? Component-Based Development and Organizational Subcultures. IEEE Transactions on Engineering Management, 50(1), 89-99. doi:10.1109/ TEM.2002.808297

Iivari, J., \& Huisman, M. (2007). The Relationship between Organizational Culture and the Deployment of Systems Development Methodologies. Management Information Systems Quarterly, 31(1), 35-58.

Iivari, J., \& Iivari, N. (2011). The Relationship between Organizational Culture and the Deployment of Agile Methods. Information and Software Technology, 53(5), 509-520. doi:10.1016/j.infsof.2010.10.008

Jackson, S. (2011). Organizational Culture and Information Systems Adoption: A Three-Perspective Approach. Information and Organization, 21(2), 57-83. doi:10.1016/j.infoandorg.2011.03.003

Kaarst-Brown, M. L., \& Robey, D. (1999). More on myth, magic and metaphor: Cultural insights into the management of information technology in organizations. Information Technology \& People, 12(2), $192-218$. doi:10.1108/09593849910267251

Kirsch, L. J. (2004). Deploying Common Systems Globally: The Dynamics of Control. Information Systems Research, 15(4), 374-395. doi:10.1287/isre.1040.0036

Koch, H., Leidner, D. E., \& Gonzalez, E. S. (2013). Digitally Enabling Social Networks: Resolving IT-Culture Conflict. Information Systems Journal, 23(6), 501-523. doi:10.1111/isj.12020

Lee, A. S., \& Baskerville, R. L. (2003). Generalizing Generalizability in Information Systems Research. Information Systems Research, 14(3), 221-243. doi:10.1287/isre.14.3.221.16560

Leidner, D. E. (2010). Globalization, Culture and Information: Towards Global Knowledge Transparency. The Journal of Strategic Information Systems, 19(2), 69-77. doi:10.1016/j.jsis.2010.02.006

Leidner, D. E., \& Kayworth, T. (2006). Review: A Review of Culture in Information Systems Research: Toward a Theory of Information Technology Culture Conflict. Management Information Systems Quarterly, 30(2), $357-399$.

Leonardi, P. M., \& Barley, S. R. (2010). Whats under construction here? Social action, materiality, and power in constructivist studies of technology and organizing. The Academy of Management Annals, 41(1), 1-51. doi:10.1080/19416521003654160

Louis, M. (1985). An Investigator's Guide to Workplace Culture. In P. Frost, L. Moore, M. Louis, C. Lundberg, \& J. Martin (Eds.), Organizational Culture (pp. 73-94). Newbury Park, CA: Sage.

Martin, J. (1992). Cultures in Organizations. Oxford: Oxford University Press.

Martin, J. (2002). Organizational Culture - Mapping the Terrain. Thousand Oaks, CA: Sage. doi: $10.4135 / 9781483328478$

Martin, J., \& Siehl, C. (1983). Organizational Culture and Counter Culture: An Uneasy Symbiosis. Organizational Dynamics, 12(2), 52-64. doi:10.1016/0090-2616(83)90033-5

McMaster, T., \& Wastell, D. (2005). Diffusion or Delusion? Challenging an IS Research Tradition. Information Technology \& People, 18(4), 383-404. doi:10.1108/09593840510633851

Meyerson, D. (1991). Acknowledging and Uncovering Ambiguities. In P. Frost, L. Moore, M. Louis, C. Lundberg, \& J. Martin (Eds.), Reframing Organizational Culture (pp. 254-270). CA: Sage. 
Meyerson, D., \& Martin, J. (1987). Cultural Change: An Integration of Three Different Views. Journal of Management Studies, 24(6), 623-647. doi:10.1111/j.1467-6486.1987.tb00466.x

Miles, M. B., \& Huberman, A. M. (1994). Qualitative Data Analysis: An Expanded Sourcebook. London: Sage.

Mishra, A. N., \& Agarwal, R. (2010). Technological Frames, Organizational Capabilities, and IT Use: An Empirical Investigation of Electronic Procurement. Information Systems Research, 21(2), 249-270. doi:10.1287/ isre. 1080.0220

Orlikowski, W. J., \& Iacono, C. S. (2001). Research Commentary: Desperately Seeking the IT in IT Research - A Call to Theorizing the IT Artefact. Information Systems Research, 12(2), 121-134. doi:10.1287/isre.12.2.121.9700

Pan, S. L., \& Tan, B. (2011). Demystifying Case Research: A Structured-Pragmatic-Situational Approach to Conducting Case Studies. Information and Organization, 21(3), 161-176. doi:10.1016/j.infoandorg.2011.07.001

Patton, M. Q. (2002). Qualitative Research and Evaluation Methods. CA: Sage.

Pfeffer, J. (1981). Power in Organizations. NY: Pitman.

Posner, B. Z., \& Munson, J. M. (1979). The Importance of Values in Understanding Organizational Behaviour. Human Resource Management, 18(3), 9-14. doi:10.1002/hrm.3930180303 PMID:10243066

Quinn, R. E., \& Rohrbaugh, J. (1983). A Spatial Model of Effectiveness Criteria: Towards a Competing Values Approach to Organizational Analysis. Management Science, 29(3), 363-377. doi:10.1287/mnsc.29.3.363

Ravishankar, M. N., Pan, S. L., \& Leidner, D. E. (2011). Examining the Strategic Alignment and Implementation Success of a KMS: A Subculture Based Multi-Level Analysis. Information Systems Research, 22(1), 39-59. doi:10.1287/isre.1080.0214

Reinecke, K., \& Bernstein, A. (2013). Knowing What a User Likes: A Design Science Approach to Interfaces that Automatically Adapt to Culture. Management Information Systems Quarterly, 37(2), 427-453.

Rivard, S., Lapointe, L., \& Kappos, A. (2011). An Organizational Culture-Based Theory of Clinical Information Systems Implementation in Hospitals. Journal of the Association for Information Systems, 12, 123-162.

Robey, D., \& Boudreau, M. (1999). Accounting for the Contradictory Consequences of Information Technology: Theoretical Directions and Methodological Implications. Information Systems Research, 10(2), 167-185. doi:10.1287/isre.10.2.167

Schein, E. H. (1985). Organizational Culture and Leadership. San Francisco, CA: Jossey-Bass.

Schein, E. H. (1992). Organizational Culture and Leadership. San Francisco, CA: Josssey-Bass Inc.

Schein, E. H. (1999). The Corporate Culture Survival Guide: Sense and Nonsense About Culture Change. CA: Josssey-Bass Inc.

Schein, E. H. (2004). Organizational Culture and Leadership (3rd ed.). CA: Josssey-Bass.

Smircich, L. (1983). Concepts of Culture and Organizational Analysis. Administrative Science Quarterly, 28(3), 339-358. doi:10.2307/2392246

The Hofstede Centre. 2014. National Culture: Dimensions. Retrieved from http://geert-hofstede.com/nationalculture.html

Van Maanen, J., \& Barley, S. (1985). Cultural Organization: Fragments of a Theory. In P. Frost, L. Moore, M. Louis, C. Lundberg, \& J. Martin (Eds.), Organizational Culture. Newbury, CA: Sage.

Venkatesh, V., Morris, M. G., Davis, G. B., \& Davis, F. (2003). User Acceptance of Information Technology: Toward a Unified View. Management Information Systems Quarterly, 27(3), 425-478.

Von Meier, A. (1999). Occupational Cultures as a Challenge to Technological Innovation. IEEE Transactions on Engineering Management, 46(1), 101-114. doi:10.1109/17.740041

Wagner, E., \& Newell, S. (2004). Best for Whom? The Tension between Best Practice ERP Packages and Diverse Epistemic Cultures in a University Context. The Journal of Strategic Information Systems, 13(4), 305-328. doi:10.1016/j.jsis.2004.11.002 
Wagner, E., \& Newell, S. (2011). Changing the Story Surrounding Enterprise Systems. In R. Galliers \& W. L. Currie (Eds.), The Oxford Handbook of Management Information Systems: Critical Perspectives and New Directions (pp. 394-414). Oxford: Oxford University Press.

Yin, R. K. (2009). Case Study Research: Design and Methods. CA: Sage.

Zhu, K., Kraemer, K. L., \& Xu, S. (2006). The Process of Innovation Assimilation by Firms in Different Countries: A Technology Diffusion Perspective on E-Business. Management Science, 52(10), 1557-1576. doi:10.1287/ mnsc. 1050.0487

Mumin Abubakre is a lecturer in management at the Nottingham Business School, Nottingham Trent University, UK. His research has been published in the Information and Management journal and in a range of peer reviewed conferences including International Conference on Information Systems, European Conference on Information Systems and other conferences in the information systems discipline. His research interests include: CrossCultural Studies of Information Systems (IS), IS/e-Business Strategies of Organizations/Governments and Global Management of IS Innovations.

Crispin Coombs is a Senior Lecturer in Information Systems in the School of Business and Economics, Loughborough University U.K. Dr Coombs' work has been published in a range of academic journals including Journal of Organizational Behavior, Journal of Vocational Behavior and European Journal of Information Systems.

M. N. Ravishankar is Professor of Globalization and Emerging Markets in the School of Business and Economics, Loughborough University, U.K. His research interests span social innovations, global sourcing of work and the digital economy of emerging markets. He has published articles in peer-reviewed scholarly journals such as Information Systems Research, Journal of World Business, European Journal of Information Systems, Information Systems Journal, Journal of Strategic Information Systems, IEEE Transactions on Engineering Management, Journal of Information Technology, Omega: An International Journal of the Institute of Management Science and Journal of Vocational Behaviour. He is currently serving as an Associate Editor at Information Systems Journal. 